\title{
ESTRATEGIAS DE MERCADEO DE LOS VENDEDORES AMBULANTES*
}

\author{
Recibido: 10 de febrero de 2014 • Aprobado: 27 de junio de 2015
}

\author{
Juan Miguel Saldarriaga Díaz** \\ Claudia Vélez-Zapata*** \\ Gabriel Betancur Ramírez $z^{* * *}$
}

\section{RESUMEN}

Este artículo tiene como propósito, identificar las estrategias de mercadeo de los vendedores ambulantes de la ciudad de Medellín. Para lograr este objetivo se realizó una observación estructurada de las prácticas de intercambio y se hizo necesaria la revisión documental para identificar las características del sector, su relación con la economía popular y la diferencia entre microempresa e informalidad. El principal hallazgo de este ejercicio investigativo es que el pensamiento intuitivo de los vendedores ambulantes da lugar a sus prácticas de mercadeo. Si bien estos emprendedores no tienen una formación académica, su intuición les permite desarrollar acciones que configuran en sí un proceso de mercadeo.

\section{PALABRAS CLAVE}

Estrategias de mercadeo, ventas ambulantes, mercadeo en las ventas ambulantes, economía informal, Colombia.

\section{CLASIFICACIÓN JEL} M31, 017.

\section{CONTENIDO}

Introducción; 1. La economía informal; 2. La economía popular; 3.Informalidad y microempresa: dos aspectos económicos diferentes; 4 . la venta ambulante como principal actividad económica en el contexto de la informalidad; 5 . Vendedores ambulantes y la aplicación del marketing intuitivo; 6. Conclusiones; Bibliografía.

Este artículo de investigación es producto del proyecto "Caracterización de la dinámica organizacional: Caso emprendimientos informales en el comercio de alimentos preparados de la ciudad de Medellín", realizada en el año 2012 por el grupo de investigación Estudios Empresariales (GEE), clasificado en Categoría B por Colciencias, Universidad Pontificia Bolivariana, Medellín, Colombia. Dicha investigación fue financiada por El Centro de investigación para el desarrollo y la innovación (CIDI) de la Universidad Pontificia Bolivariana. Medellín, Colombia.

* Publicista, Universidad Pontificia Bolivariana, Medellín, Colombia. Especialista en Gerencia de Mercadeo, Universidad Pontificia Bolivariana, Medellín, Colombia. Asistente del grupo de investigación Estudios Empresariales (GEE), Escuela de Ciencias Estratégicas, Universidad Pontificia Bolivariana, Medellín, Colombia. Profesional de Alianzas y Patrocinios de Mercadeo y promoción Universitaria en la Universidad Pontificia Bolivariana, Medellín, Colombia. Circular lera \# 70 -01. Tel.: (+574) 4488388. Correo electrónico: jsaldarriagal3@gmail.com.

... Profesional en alta gerencia de mercadeo, Escuela Colombiana de Mercadotecnia, Medellín, Colombia. Magíster en Administración, Universidad EAFIT, Medellín, Colombia. Doctora en Administración, Universidad San Pablo CEU, Madrid, España. Profesora Titular de la Facultad de Administración e Investigadora del Grupo Estudios Empresariales (GEE), Universidad Pontificia Bolivariana, Medellín, Colombia. Circular lera \# 70 -01. Tel.: (+574) 4488388. Correo electrónico: claudiap.velez@upb.edu.co.

...* Licenciado en Matemáticas, Física, Universidad de Antioquia, Medellín Colombia. Candidato a magíster en Matemática Aplicada, Universidad EAFIT, Medellín, Colombia. Coordinador de Autoevaluación, Escuela de Ciencias Estratégicas, Universidad Pontificia Bolivariana. Profesor e Investigador del Grupo Estudios Empresariales (GEE). Universidad Pontificia Bolivariana, Medellín, Antioquia. Circular la \# 70 -01. Tel.: (+574) 4488388. Correo electrónico: gbetancur@upb.edu.co. 


\section{STREET SELLERS MARKETING STRATEGIES}

\section{ABSTRACT}

The main objective of this article is to identify marketing strategies used by street sellers in the city of Medellin. In order to reach this objective a structured observation was required for exchange practices, their relation with the popular economy and the difference between micro business and informality. The main finding of this research was that the intuitive thinking of the street sellers opens space to marketing practices. And even though this entrepreneurs don't count with academic education, their intuition allows them to develop actions that become a marketing process.

\section{KEY WORDS}

Marketing strategy, street sales, street sales marketing, Informal economy, Colombia

\section{JEL CLASSIFICATION}

M31, 017.

\section{CONTENT}

Introduction; 1.Informal economy; 2.Popular economy; 3.Informality and micro-businesses: Two different economic aspects; 4 . Street selling as main economic activity under the informality context; 5 . Street sellers and intuitive marketing application; 6. Conclusions; Bibliography.

\section{ESTRATÉGIAS DE MARKETING DOS VENDEDORES AMBULANTES RESUMO}

Este artigo tem como propósito, identificar as estratégias de marketing dos vendedores ambulantes da cidade de Medellín. Para conseguir este objetivo se realizou uma observação estruturada das práticas de intercâmbio e se fez necessária a revisão documental para identificar as características do setor, sua relação com a economia popular e a diferença entre microempresa e informalidade. O principal descoberta deste exercício investigativo é que o pensamento intuitivo dos vendedores ambulantes dá lugar a suas práticas de marketing. Se bem estes empreendedores não têm uma formação acadêmica, sua intuição lhes permite desenvolver ações que configuram em si um processo de marketing.

\section{PALAVRAS CHAVE}

Estratégias de marketing, vendas ambulantes, marketing nas vendas ambulantes, economia informal, Colômbia.

\section{CLASSIFICAÇÃO JEL}

M31, 017.

\section{CONTEÚDO}

Introdução; 1. A economia informal; 2. A economia popular; 3.Informalidade e microempresa: dois aspectos económicos diferentes; 4 . a venta ambulante como principal atividade económica no contexto da informalidade; 5 . Vendedores ambulantes e a aplicação do marketing intuitivo; 6. Conclusões; Bibliografia. 


\section{INTRODUCCIÓN}

La economía informal, conocida también como economía popular, subterránea, negra o ilícita ocupa entre el 48,3 \% y el 55,5 \% del total de la población trabajadora en Colombia; así lo argumentan Gómez, Gómez y Borráez (2005). La informalidad responde a una necesidad de sustento que no ha sido posible cubrir en el mercado laboral formalizado en un territorio. La OIT (2005) plantea que responde también a los altos costos del proceso de formalización de una empresa, los desajustes estructurales de la oferta y la demanda de la mano de obra, la baja productividad y los escasos ingresos de los trabajadores.

Las personas acceden a este tipo de economía por diversos motivos, entre ellos, la búsqueda de una mejor calidad de vida para ellos y sus familias, las facilidades de entrada (ya que el capital inicial es bajo y asequible para cualquier persona), los rápidos ingresos que reciben en corto tiempo y en algunos casos porque es su única oportunidad para satisfacer sus necesidades básicas.

Factores como el género, la edad, el desempleo, la migración, el nivel educativo, entre otros, han llevado a las personas a buscar sus propias fuentes de ingresos. En la literatura sobre la economía informal, diversos autores, entre estos la OIT (2005), Portes y Haller (2004), Miranda y Rizo (2010) y Ochoa y Ordóñez (2004), han tratado de darle una tipología a estos negocios con el fin de lograr una clasificación que permita entender el modelo económico, los productos ofertados, los diversos servicios, la forma de subsistencia y todos los aspectos legales que afectan el desarrollo de sus mercados y no les permiten vivir en armonía con el Estado ni con la comunidad bajos las formas de la economía formal.

No obstante, en nuestro país y en especial para el departamento de Antioquia son poco exploradas desde la perspectiva del mercadeo las características, las estrategias y el funcionamiento de la economía informal. Dado que más de la mitad de la población trabajadora en Colombia, según Gómez, Gómez y Borráez (2005), tiene empleos informales, es importante conocer las condiciones que permiten a los vendedores ambulantes ser rentables, perdurar en el tiempo e interactuar con sus mercados y clientes.

Este trabajo identifica las estrategias de mercadeo de los vendedores ambulantes en la economía informal, evaluando cómo funciona, quiénes son sus actores y cuáles son sus características; para encontrar dicha información, se rastrearon artículos relacionados con el tema en la base de datos de EBSCO, empleando los términos economía popular, informal o solidaria, mercadeo y ventas y combinaciones de estas. Adicionalmente, se buscó manualmente en google académico con el fin de ampliar la bibliografía. 
Se inicia con una definición del sector a través de la revisión bibliográfica, luego se procede a la observación estructurada a fin de resolver la pregunta principal de este artículo: ¿cuáles son las prácticas de mercadeo que desarrollan los vendedores ambulantes, en un contexto de intercambio, que les permite a sus unidades de negocio subsistir generando una entrada rentable para suplir sus necesidades y las de sus familias? Algunas preguntas que guiaron la observación fueron: ¿cómo dichos negocios generan rentabilidad?, ¿cómo diseñan y promocionan sus productos?, ¿qué aspectos se consideran en la fijación de los precios?, ¿cuáles son los criterios para seleccionar su punto de venta?, ¿cómo subsisten en el tiempo?, ¿cómo crean su marca? y ¿cómo manejan sus comunicaciones?

Cabe señalar que este trabajo no hace un estudio amplio de la economía informal, el empleo informal o la informalidad empresarial, sino que se centra en las ventas ambulantes, una parte de la economía informal.

El principal resultado encontrado es que dichas prácticas parten del pensamiento intuitivo de los vendedores ambulantes, y pueden denominarse mercadeo intuitivo. Dicho mercadeo, como dicen Ardila y Hoyos y Sabogal (2010), hace referencia a la utilización de estrategias y tácticas mercantiles que aplican las empresas, protagonistas de la economía informal y popular, sin tener conocimiento previo, profundo y formal sobre su aplicación y efectos en el entorno, logrando así sostener sus negocios por años y recibiendo beneficios económicos por ese intercambio. Este mercadeo nace de la experiencia; sus tácticas surgen como respuesta a fenómenos observables en la sociedad y su aplicación se da por la necesidad misma de completar una cuota de ventas significativa para sostener su hogar y cumplir las necesidades básicas.

Este artículo se divide en seis secciones sin incluir la introducción. En la primera sección se aborda el concepto de economía informal; en la segunda, el tema relacionado con la economía popular; en la tercera, se muestra la relación y diferencias entre informalidad y microempresa; la cuarta sección presenta un análisis de la venta ambulante como la principal actividad económica dentro de la informalidad; en la quinta sección se explica cómo los vendedores ambulantes aplican las estrategias del mercadeo y se presentan los resultados, finalmente, se exponen las conclusiones del trabajo.

\section{LA ECONOMÍA INFORMAL}

Antes de mencionar cómo funcionan dichas prácticas, es importante conocer el sector que lo contiene. Portes y Haller (2004) dicen que la economía informal nace luego de unos estudios realizados en África por el antropólogo económico Keith Hart mientras analizaba el mercado laboral urbano en ese continente. Dichos es- 
tudios, según Peres (2010, p. 59), utilizaron la siguiente definición: "El sector informal describe las actividades económicas de pequeña y mediana escala, que cuenta con mano de obra intensiva, tiene baja productividad y constituye la principal fuente de empleo e ingresos para los países en vía de desarrollo".

La informalidad es un eslabón importante en la cadena económica porque tiene un alto porcentaje de participación en el total de la población. En Latinoamérica la informalidad representa el 56 \% de la sociedad. Gómez, Gómez y Borráez (2005) dicen que en Colombia representa entre el 48,3 \% y el 55,5\%, y en Medellín, según la Encuesta Integrada de Hogares realizada por el DANE para el año 2010, se calculó un $52,28 \%$ en la tasa de informalidad por características económicas (Guataquí, García y Rodríguez, 2011). La OIT (2005) dice que el crecimiento constante de este sector está asociado con el aumento de la pobreza, el ajuste estructural, las privatizaciones y otras consecuencias derivadas de la globalización.

El término informal nace en contraposición a la formalidad, y su definición está relacionada con la ilegalidad. Se reconoce como un problema que afecta al país ya que las personas inmersas en estos sectores no cuentan con los servicios mínimos de salud y pensiones, y están expuestas a condiciones precarias de trabajo y duras jornadas de trabajo. Además, son un sector descuidado y desprotegido, sus trabajadores no están afiliados a sindicatos, seguros o rentas y tampoco cuentan con protección del Estado; sin embargo, procuran una vida digna, de acuerdo con Mires (1989).

\section{LA ECONOMÍA POPULAR}

Dentro de la economía informal se encuentra la economía popular, también conocida como economía subterránea. Según Sarria y Tiribia (2003, p. 173):

[...] es el conjunto de actividades económicas y prácticas sociales desarrolladas por sectores populares con miras a garantizar, a través de la utilización de su propia fuerza de trabajo y de los recursos disponibles, la satisfacción de las necesidades básicas, tanto materiales como inmateriales.

Para la OIT (2005) la economía popular es asociada con negocios clandestinos, ilegalidad, pobreza, desempleo o autoempleo, trabajo negro, cuenta propia, autogestión, supervivencia y rebusque. Según el CESOP (2005, p. 3):

[.. .] la economía informal es un fenómeno muy amplio, pues incluye actividades en los distintos sectores de la economía. Sin embargo, la actividad informal en el comercio, particularmente, en la forma de vendedores ambulantes, es la más conocida debido a su presencia en la vida cotidiana de muchas personas. 
Parte de estos negocios son catalogados como clandestinos por no tener un Registro Único Tributario (RUT) ni estar registrados en Cámara de Comercio; esto, en síntesis, corresponde a la no formalización de la empresa en el marco legal que determine un territorio.

La motivación de las personas para ingresar a la economía informal es generada por la necesidad de sobrevivir y buscar una calidad de vida propia y para sus cercanos; es por ello que se ven, como dice la OIT (2010), negocios donde miembros de la misma familia aportan su tiempo y fuerza de trabajo para mantener esa unidad empresaria. Estas personas utilizan los empleos informales de dos maneras: una de ellas es como su principal y única fuente de ingresos, en la cual ellos son los principales empleados y empleadores, representan al vendedor, al administrador, al contador, al sub-contratador y a las diferentes áreas de la empresa incluyendo la de mercadeo. Por otro lado, Sarria y Tiribia (2003) enuncian que hay quienes la utilizan como fuente de ingresos complementaria, así que circulan entre las dos economías, la formal y la informal, consiguiendo aumentar sus ingresos.

Otro motivo que genera el crecimiento de este sector es el desplazamiento de personas del sector rural; como dicen Jaramillo, Villa y Sánchez (2004), vale recordar, en ese sentido, que según el IDCM (Internal Despacement Monitoring Centre) en 2014, Colombia era el segundo país con más desplazados en el mundo, esto es, sobre la base de 45 millones de colombianos, 1 de cada 10 han sido desplazados. Los campesinos van a las ciudades en busca de oportunidades debido a problemas de conflicto armado en el país. Estas personas, al llegar a la ciudad, buscan empleos relacionados con su labor en el campo, y deciden trabajar como albañiles, trabajadores rasos, recicladores o, por ejemplo, montan su propio negocio, como comerciantes ambulantes y/o callejeros.

\section{INFORMALIDAD Y MICROEMPRESA: DOS ASPECTOS ECONÓMICOS DIFERENTES}

La economía informal se caracteriza, en parte, porque dispone de poco o ningún capital, utiliza técnicas rudimentarias y mano de obra en raras ocasiones calificada; quienes trabajan en ello suelen obtener ingresos muy bajos e irregulares, y su empleo es bastante inestable, argumenta Camargo (2005). La inversión inicial para una empresa informal no excede los 3.000 .000 de pesos en contraposición a los elevados costos de creación de empresas en el sector formal. Es por ello, según Ochoa y Ordóñez (2004), que en muchos casos la constitución formal se desestimula y muchas empresas deciden permanecer en la informalidad.

En Colombia, el Departamento Administrativo Nacional de Estadística-DANE(ver Tokman, 2001) enuncia que en la economía informal se distinguen negocios con las siguientes características: 
- Un asalariado o patrón dueño de un negocio con menos de 10 trabajadores.

- Un modelo de negocio doméstico, llamado también cuenta propia.

- Los ayudantes o trabajadores son familiares que no siempre reciben remuneración.

Por otra parte, el Consejo Nacional de Política Económica y Social de la República de Colombia, según el DNP (2007), hace una descripción de las micro, pequeñas y medianas empresas ubicadas en el país, y muchas de sus características concuerdan con las descritas en el sector informal y la economía popular. Entre las más relevantes para el caso de las Microempresas, se destacan:
a) Sus altos niveles de informalidad
b) Sus bajos niveles de asociactividad
c) La estrechez de los mercados a los que dirigen sus productos
d) El bajo nivel tecnológico y de formación de sus recursos humanos
e) El limitado acceso al sector financiero.

Según Cárdenas y Mejía (2007), los niveles de informalidad aumentan a medida de que la empresa es más pequeña; estas reflejan su baja capacidad para llevar a cabo actividades rentables y con potencial de expansión que les permitan cubrir los costos de operar en el sector formal de la economía; según el DNP (2007), su acceso a la tecnología es restringido por lo que se pueden ver pequeñas empresas con materiales y maquinaria atrasadas y casi obsoletas, así como personas no calificadas e inexpertas en todo el tema de ventas, preparación de sus productos y sin un mayor conocimiento del servicio al cliente. Un porcentaje significativo de estas empresas vende sus productos y servicios en nichos de mercado locales; sus consumidores son, en su mayoría, de bajos ingresos, y los requisitos de calidad, precio y volumen son poco exigentes.

Basados en estas descripciones, es posible considerar una relación directa entre la microempresa y la informalidad. No obstante no son iguales, ya que no todas las microempresas nacen en la informalidad y se desarrollan bajo márgenes de ilegalidad. Los países han diseñado soluciones creativas que consisten en incluir una gran parte de personas que poseen estas unidades de negocio en algún tipo de sistema de protección social, buscan reducir los costos de formalización de las empresas, crean entidades de apoyo económico y social e incentivos para quienes generen nuevos empleos, especialmente para los grupos vulnerables, como los trabajadores jóvenes menores de 28 años, dice la OIT (2013). 


\section{LA VENTA AMBULANTE COMO PRINCIPAL ACTIVIDAD ECONÓMICA EN EL CONTEXTO DE LA INFORMALIDAD}

La venta ambulante incluye diferentes actividades comerciales por lo cual es necesario recurrir a una agrupación de negocios de acuerdo con sus similitudes estructurales, de bienes y de servicios. Los vendedores ambulantes no son un grupo homogéneo; su categorización se hace con base en el tipo de productos que comercializan, el lugar y los medios que utilizan para vender, así como su estatus de formalidad. El oficio de la venta ambulante puede ser una fuente de trabajo primario a tiempo completo o un trabajo secundario a tiempo parcial (por ejemplo, las ventas ambulantes de estudiantes universitarios dentro de las instituciones de educación). A continuación, se presentan en la tabla las distintas tipologías de vendedores ambulantes:

Tabla 1. Tipología de vendedores ambulantes

\begin{tabular}{|c|c|}
\hline \multicolumn{2}{|c|}{ Tipos de productos: ¿̇ué venden? } \\
\hline $\begin{array}{l}\text { - } \text { Comida: frutas y vegetales } \\
\text { - Alimentos preparados } \\
\text { - Dulces y golosinas } \\
\text { - Helados y paletas }\end{array}$ & $\begin{array}{l}\text { - } \text { Cigarrillos y fósforos } \\
\text { - Periódicos y revistas } \\
\text { - Bienes manufacturados (ropa, calzado) } \\
\text { - Bienes de segunda mano (electrodomésticos, } \\
\text { vajilla) }\end{array}$ \\
\hline \multicolumn{2}{|c|}{ Ubicación geográfica del vendedor ambulante: ¿dónde venden sus productos? } \\
\hline $\begin{array}{l}\text { - Sistema de mercados al aire libre en áreas } \\
\text { designadas en días designados (mercadillos } \\
\text { y mercado de pulgas) } \\
\text { - Concentración de vendedores en áreas parti- } \\
\text { culares legitimadas por el uso y por entidades } \\
\text { de control territorial según la región (centro } \\
\text { de la ciudad, parques o plazoletas en áreas } \\
\text { residenciales, universidades y plazas de } \\
\text { mercado) } \\
\text { - Esquinas y aceras de la ciudad. }\end{array}$ & $\begin{array}{l}\text { - Espacios públicos de alto tráfico (estaciones } \\
\text { del metro, paradas de autobuses, acopios de } \\
\text { taxi) } \\
\text { - Sitios de construcción } \\
\text { - Complejos deportivos } \\
\text { - En el hogar o ventas de ventanilla. }\end{array}$ \\
\hline \multicolumn{2}{|c|}{ Infraestructura de la venta ambulante: ¿qué muebles utilizan para vender sus productos? } \\
\hline $\begin{array}{l}\text { - Canastas o baldes puestos en el piso o que } \\
\text { se cargan en la cabeza o en el cuerpo. } \\
\text { - Mantas u otro material esparcido en el suelo } \\
\text { - Bancos o mesas }\end{array}$ & $\begin{array}{l}\text { - } \text { Bicicleta } \\
\text { - Carrito que se empuja con ruedas } \\
\text { - Venta ambulante sobre ruedas } \\
\text { - Puerta o ventana de una residencia } \\
\text { - Carpa fijas, puestos o kioscos }\end{array}$ \\
\hline
\end{tabular}


Grado de formalidad laboral: ¿trabajo independiente o dependiente?

- Auto-empleados independientes: con o sin empleados.

Trabajadores semi-independientes (agentes por comisión)

- Empleados dependientes: asalariados para otros vendedores ambulantes o comerciantes al mayoreo o al menudeo

Fuente: adaptación con base en información de la OIT $(2002$, p. 50) y el CESOP $(2005$, p. 5).

Miranda y Rizo (2010) proponen otro tipo de clasificación de acuerdo al tipo de ingresos de estos negocios informales:

a) Comercio informal de subsistencia: hace referencia a los establecimientos conformados por personas pertenecientes al sector informal que deciden emprender en este tipo de negocios como recurso de supervivencia ya que están inmersos en la pobreza y sus condiciones de vida son rudimentarias y bajas. No poseen ingresos representativos, son explotados por un patrón y debido a sus bajos niveles educativos y pocas habilidades no pueden ser empleados en el sector formal.

b) Comercio informal de rentabilidad: la autonomía laboral y el poder recibir mejores ingresos en este tipo de trabajos lleva a algunos miembros de la comunidad a renunciar al sector formal e incorporarse en esta economía subterránea; en este caso no se hace por el simple hecho de suplir las necesidades básicas sino de buscar una mayor riqueza con un menor esfuerzo y una clara evasión de las leyes emitidas por el Estado.

Dentro de las características del sector informal, algunos puntos negativos se ven reflejados en la asociación entre ilegalidad e informalidad, lo que confunde a las autoridades y fuerzas públicas. El CESOP (2005, p. 16) afirma que "la falta de registro de las actividades complica el monitoreo de prácticas ilegales".

Otras características de los negocios del sector informal y los vendedores ambulantes en particular son: la evasión de impuestos, el no pago de servicios públicos, el aprovechamiento inusual del espacio público, la mala práctica en reglamentos sanitarios, entre ellos, el uso del agua potable, muchas veces inaccesible para esta población, la acumulación de basuras, los desechos orgánicos lo que deriva en enfermedades para sus consumidores y altos costos para las entidades de salud al tratar estos casos.

Además de lo anterior, está el bajo o inexistente uso de tecnologías para sus procesos, administraciones y transacciones, manejo de dineros y recursos monetarios sin afiliación al sistema financiero. Estas personas guardan el dinero en 
sus casas, y día a día liquidan trabajadores y compran los materiales necesarios para iniciar el negocio al día siguiente; la mayor parte de la fuerza de trabajo son sometidos a excesivas horas de trabajo y poco descanso, son negocios con bajo capital y remuneraciones, dice CESOP (2005), sufren en repetidas ocasiones por abusos, extorsiones y/o desalojos por la violencia en la ciudades o las autoridades encargadas de controlar el espacio público en la ciudad; su inspiración para iniciar su negocio es la imitación o la necesidad, ven a algún vecino que comenzó vendiendo algún tipo de mercancía o alimentos en la calle y a generar ingresos significativos para su familia y evalúan sus habilidades para saber qué pueden vender también, en qué lugar, en cuál horario, con qué estructuras y emprenden su propio negocio.

\section{VENDEDORES AMBULANTES Y LA APLICACIÓN DEL MARKETING INTUITIVO}

Los vendedores ambulantes son emprendedores no formalizados que comercializan productos y servicios teniendo como lugar de operación la vía pública. La manera de administrar su negocio es producto del conocimiento empírico que desarrollan cada día. Una sola persona puede ser la encargada de todas las funciones administrativas de su venta ambulante, desde planear, controlar, buscar los recursos, vender, prestar un servicio al cliente, manejo de caja, control de calidad, apropiación de un espacio público y promociones. Muchos de estos negocios son móviles, la persona surte sus insumos, se encarga en casa de adelantar algunos procesos incluyendo la limpieza de su estructura y, en el caso de las comidas callejeras, de preparar algunos alimentos para que a la hora de su venta solo tenga que ensamblarlos y brindárselos a sus clientes.

Es común ver cómo estas personas ofrecen una cantidad de productos a muy bajo costo y cerca a lugares de alta circulación de personas como lo son las universidades, colegios, empresas, eventos culturales o artísticos y sitios deportivos. Según Arámbulo III y otros (1995, p. 98) "los ingresos medios de un trabajador en el sector de la venta callejera de alimentos son más altos, a veces hasta tres o incluso 10 veces mayores que el salario mínimo nacional".

Su estrategia radica en comercializar productos de consumo masivo; comida, licores, cigarrillos, comunicaciones, juguetería y entretenimiento hacen parte de la oferta callejera.

Algunos de estos negociantes salen en horas de alta circulación de personas y en sitios donde se congrega la gente. Así aprovechan para garantizar e incrementar sus ventas y el ingreso esperado. En textos académicos sobre mercadeo se encuentra poca evidencia sobre este tema; no obstante, es una realidad innegable que amerita ser investigada. 
Términos como mercadeo al ojo, mercadeo emprendedor, mercadeo de ensayoerror son poco utilizados ya que van en contra de la academia mercantil que habla desde autores reconocidos como Philip Kotler, Peter Drucker o David Aaker con esquemas más estructurados y registrados en diversos libros, tesis, artículos y congresos. Kotler y Armstrong (2013) afirman que "el marketing es un proceso social y administrativo mediante el cual grupos e individuos obtienen lo que necesitan y desean a través de generar, ofrecer e intercambiar productos de valor con sus semejantes". Y para Stanton, Etzel y Walker (2007), "el marketing es un sistema total de actividades de negocios ideado para planear productos satisfactores de necesidades, asignarles precios, promover y distribuirlos a los mercados meta, a fin de lograr los objetivos de la organización".

Vargas (2011) alude que el mercadeo es un conjunto de actividades que consisten en:

a) Identificar una necesidad latente en el mercado de acuerdo con los deseos de la población.

b) Al identificar esa necesidad se realiza una planeación, y de acuerdo con las posibilidades de la empresa o el individuo se produce un producto o servicio bajo un nombre (marca) para ese público definido.

c) Luego se localiza el lugar o los medios por los cuales se va a llevar esta nueva marca al mercado y a sus consumidores.

d) El fin de esta actividad es satisfacer la necesidad encontrada, y a cambio de lo ofertado se espera recibir un valor (beneficio) por parte de la organización.

El mercadeo intuitivo no contradice ni desaprueba las definiciones creadas por la academia; por el contrario, afirma sus ideas, pero las aplica desde los principios más básicos y rudimentarios. En palabras de Ardila, Hoyos y Sabogal (2010), este mercadeo está asociado a sus orígenes, es decir, la cultura donde nace, las costumbres de la región, las tradiciones de la zona y la informalidad; normalmente se evidencia en plazas de mercado, salidas de eventos, universidades, territorios empresariales o dentro de los barrios, siempre caracterizados por estar ubicados en la vía pública y al aire libre; personas -según Ardila, Hoyos y Sabogal (2010) llevadas por la necesidad el rebusque -o la corazonada- deciden poner a la vera del camino variados productos.

El mercadeo intuitivo es ese tipo de estrategia que utilizan y aplican las microempresas, los emprendedores y los vendedores ambulantes, protagonistas de la economía informal y popular, como dicen Ardila, Hoyos y Sabogal (2010, p. 137) "sin tener conocimiento previo, profundo y formal sobre su aplicación y efectos en el entorno macroeconómico". 
Dicha intuición se basa en la experiencia adquirida con el paso de los años y la observación del entorno.

El mercadeo intuitivo o no formulado, según Ardila, Hoyos y Sabogal (2010), es aprendido por las personas dentro del mismo círculo social o familiar y pasa de generación en generación. Su transmisión se da por medio de conversaciones entre colegas donde cada individuo comparte su éxito personal y el tipo de prácticas de mercadeo utilizadas (que no se encuentran en los libros sino que nacen del día a día) aprendidas por técnicas de ensayo-error, por el aprovechamiento de las oportunidades que brinda el entorno y de conversaciones con sus clientes. Poco a poco cada una de sus unidades comerciales va dando sus frutos moldeándose al estilo de vida de su dueño y a las necesidades que muestre el medio donde se desenvuelven.

Los vendedores informales realizan preguntas y sugerencias a sus clientes acerca de los productos que comercializan: ¿cómo le pareció el producto?, si lleva ese, le regalamos la bebida, por ejemplo; así que promociones, descuentos, pague menos y lleve más, paquetes de productos y servicios adicionales son ofrecidos a diario con el fin de lograr atraer clientes nuevos y retener a sus antiguos consumidores. El mercadeo desde la óptica económica está guiado por la ley y análisis de la oferta y la demanda; desde la perspectiva estratégica se ha transformado en un análisis de la demanda y la oferta, es decir, la creación de un producto o servicio va de acuerdo con lo que exijan el mercado y sus consumidores, evitando que se lancen artículos que no tengan aceptación y estén destinados a desaparecer.

De acuerdo con Ardila, Hoyos y Sabogal (2010), los actores de la economía informal aplican este principio sin una reflexión académica previa, enfrentando decisiones de segmentación, el dilema de si tener un negocio prestigioso o uno masificado, la ubicación del punto de venta, el tipo de producto ofertado, las horas en las cuales se abrirá y cerrará el establecimiento, los servicios que prestará, el nombre de su empresa y el precio de sus productos. Según Tokman (2001), citado por Miranda y Rizo (2010), el sector informal forma su propio nicho de mercado y se convierte en productor de bienes y servicios aprovechando la cercanía que permite este tipo de negocios a su consumidor final.

Ardila, Hoyos y Sabogal (2010) proponen tres tipos del mercadeo luego de analizar autores como Kotler (2013) y Druker (2010): un mercadeo intuitivo o emprendedor, un mercadeo académico o formulado y un mercadeo disruptor o intrépido.

La utilización de nuevas técnicas se da para enfrentar el mercado cambiante y la competencia, es decir, siguiendo a Ardila, Hoyos y Sabogal (2010, p. 138): "El concepto de lo simbólico en la cultura facilita la inserción de lo intuitivo, el sentido común y lo instintivo como criterios válidos en el actuar del mundo de los negocios". 
Para conocer esos fenómenos ocultos es necesaria la utilización de métodos como la etnometodología, rama de la sociología que estudia el sentido común a través del cual los miembros de la sociedad coordinan, estructuran y entienden sus actividades diarias, según Firth (2010).

El sector informal es caracterizado por la baja capacitación en conceptos y teorías como el mercadeo y la administración, lo que lleva a que las personas actúen sobre lo que conocen, lo que dicta su conciencia de acuerdo con su experiencia, lo que han observado en sus semejantes o basándose en errores pasados y experiencias positivas de sus colegas. La búsqueda constante del éxito, un mejor futuro propio y para sus familias son las razones principales para encontrar los métodos y las prácticas más adecuadas para explotar de la mejor manera sus negocios.

Tabla 2. Las 4 p aplicadas a la economía informal

\begin{tabular}{|c|c|c|c|}
\hline $\begin{array}{l}\text { Hace referencia a la ne- } \\
\text { cesidad encontrada por } \\
\text { el emprendedor } \\
\text { Servicio y/u objeto comer- } \\
\text { cializable por el vendedor } \\
\text { Tipología del producto, } \\
\text { bien o servicio }\end{array}$ & $\begin{array}{l}\text { En elárea publicitaria y de } \\
\text { comunicación no hacen } \\
\text { mucho énfasis debido a } \\
\text { los costos de ésta y el } \\
\text { desconocimiento del im- } \\
\text { pacto. Sus promociones } \\
\text { son de tipo: } \\
\text { - 2xl } \\
\text { - Combos } \\
\text { - Descuentos por can- } \\
\text { tidad } \\
\text { - regateo }\end{array}$ & $\begin{array}{l}\text { Cualquier zona del espa- } \\
\text { cio público, aceras, calles, } \\
\text { vías, exterior de universi- } \\
\text { dades, eventos públicos, } \\
\text { complejos deportivos, } \\
\text { autobuses }\end{array}$ & $\begin{array}{l}\text { El valor es asignado de } \\
\text { acuerdo a la ganacia de- } \\
\text { seada y a los costos de } \\
\text { producción y elaboración } \\
\text { del bien o servicio. }\end{array}$ \\
\hline PRODUCTO & $\begin{array}{l}\text { PROMOCIÓN Y } \\
\text { COMUNICACIÓN } \\
\text { COMERCIAL }\end{array}$ & PLAZA O DISTRIBUCIÓN & PRECIO \\
\hline
\end{tabular}

Fuente: elaboración propia

El Marketing mix, término utilizado por Borden (1964), o mezcla de mercadeo, como también se conoce a las 4 variables (o 4 pes) que contienen el mercadeo, ayuda a la empresa, marca o servicio a describir y analizar cómo dirigir su actividad económica teniendo en cuenta las necesidades de sus consumidores. A continuación, se definen estas variables de acuerdo con lo mencionado anteriormente en el sector informal y la economía popular. Dicha información se recopiló luego de realizar una observación estructurada de las prácticas de intercambio en vendedores ambulantes de la ciudad de Medellín:

Producto: debido a las habilidades precarias y bajo nivel académico de las personas inmersas en esta economía, los productos son simples, y principalmente 
del sector alimentos. Son elaborados en casa o en el mismo punto de venta, son de fácil preparación y se caracterizan por la rápida entrega a sus clientes.

Promoción y comunicación comercial: su comunicación comercial es baja, asignan una marca al negocio en ocasiones y está referenciado al nombre de la persona dueña del negocio; se distinguen entre sus consumidores por el tipo de producto que distribuyen. No hacen uso del recurso publicitario debido a sus costos, el desconocimiento del impacto que podría generar este tipo de propuestas comunicacionales y tampoco las ven como algo necesario. Desde un enfoque gráfico son pobres en diseño de imagen corporativa, piezas comunicativas y conceptualización, ya que son negocios en los cuales lo más representativo son las ventas que se puedan generar y es allí donde invierten su fuerza laboral, creando productos de fácil acceso, comercialización y con un público que los acepta y paga por ellos. Se podría decir que su estrategia funciona como mercadeo directo donde son pocas las barreras que hay entre el cliente, el producto y el productor; su mayor fuerza comunicacional está en el "voz a voz", y en el Good will que genera entre sus consumidores. Otro punto importante es la capacidad de generar promociones atractivas para sus clientes, que son traducidas en descuentos por cantidad, combos más económicos, dos por uno o créditos. El valor de las promociones es motivado por el beneficio económico, lo que busca es generar mayores ventas en el menor tiempo posible.

Plaza o distribución: existen 2 tipos de punto de venta para el comercio informal: las estructuras móviles (ambulantes) y las estructuras fijas. Estos comerciantes buscan lugares cercanos a universidades, construcciones, placas deportivas, vías públicas, aceras, complejos empresariales, atractivos turísticos, unidades cerradas para llevar sus negocios e impactar un mayor número de personas (clientes).

Un problema presente en estos negocios es que la mayoría no cuenta con las condiciones necesarias para asegurar que los productos, el almacenamiento y la fabricación cumplan con los estándares de calidad exigidos por la ley.

Por otro lado, se encuentra el problema con la apropiación ilegal del espacio público, la evasión de impuestos y el uso prohibido de los servicios como agua y luz. Entidades gubernamentales como el INVIMA que se encarga de la vigilancia de medicamentos y alimentos, la DIAN, encargada del tema de los impuestos, el INS encargado del tema de la salud o Espacio Público, encargado de velar, actualizar y controlar la base de datos de los comerciantes codificados y evitar fraudes y mala utilización de lugares dentro de la ciudad, tienen que hacer constantes chequeos y controles a este tipo de negocios.

Precio: Buscan generar un valor atractivo para sus clientes, pues saben que al ofertar productos a bajos costos llamarán la atención de su público y lograrán 
alcanzar las metas en ventas para que el negocio se pueda sostener. Los insumos necesarios para la fabricación del producto influyen en el valor final que este tendrá en el mercado, al igual que sus competidores cercanos.

\section{CONCLUSIONES}

La economía informal nace debido a factores como el desempleo, la falta de ofertas laborales adecuadas en el sector formal, el difícil acceso a la educación superior, los desplazamientos causados por el conflicto armado, el rechazo de las mujeres como unidades productivas, la edad como determinante de las capacidades de una persona y, lo más importante, la necesidad de trabajar, subsistir y generar el capital suficiente para suplir las necesidades básicas propias y de sus familias.

En cuanto a la legalidad, los vendedores ambulantes presentan dificultades con entidades de control del Estado, espacio público y personas encargados de velar por la seguridad y descontaminación de los alimentos. Al ser negocios que abusan de los servicios públicos como el agua, la luz y la energía, son señaladas como actividades económicas que están al margen de la ilegalidad. Esto se debe a que no cuentan con los recursos suficientes para garantizar la correcta manipulación de alimentos, productos o servicios; sus estándares de calidad son bajos y son tildados como peligrosos para el consumo de las personas. Asimismo, al apropiarse sin ningún permiso del espacio público, de aceras, carreteras, y demás son obligados a pagar extorsiones o ser desmantelados dificultando su correcto funcionamiento y rentabilidad.

Luego de analizar el sector, su funcionamiento, el tipo de bienes que distribuyen, el lugar donde realizan sus ventas y sus públicos de interés, se concluye que el mejor término para describir las prácticas aplicadas por estos negocios es el mercadeo intuitivo, el cual es utilizando y aplicado por los vendedores ambulantes, miembros de la economía informal y popular.

Estas prácticas van desde la asignación de precios, hasta la selección de los puntos de distribución, el tipo de productos y sus estrategias comunicacionales y promocionales, todo ello partiendo de la intuición y la imitación. Este modelo de mercadeo tiene muchas falencias porque no realiza una investigación previa de los diversos factores del negocio, no se hace un adecuado proceso de planeación, aplica sus técnicas sin medir los márgenes de error, no calcula el alcance de sus impactos y su enfoque no está orientado hacia la satisfacción del cliente. Al no aplicar la academia ni estudiar a fondo el mercado antes de comenzar su negocio, sus estrategias no alcanzan las metas deseadas, y la forma más fácil de encaminar sus negocios es por tácticas de ensayo error o consejos de sus semejantes. 
Todavía queda mucho por conocer acerca de la economía informal y popular, y queda mucho por desmitificar. Esta actividad se desarrolla en ámbitos de mercado e intercambio incluyendo oferentes, clientes, necesidades, deseos y satisfacción, conceptos que son objeto del mercadeo. Día a día la práctica nutre el bagaje teórico, el mercado cambia, los públicos maduran y sus necesidades varían.

La venta ambulante es una actividad económica importante en los países latinoamericanos, y precisa de una mayor atención en la investigación y en la academia. Para estudiantes de las áreas de gestión como mercadeo y administración este tipo de comerciantes pueden ser menospreciados como agentes económicos y como gestores de estrategias y prácticas que bien pueden ser comprendidas desde el andamiaje teórico y técnico de la disciplina del mercadeo y la administración.

\section{BIBLIOGRAFÍA}

Ardila Lozada, Ignacio; Hoyos Rendón, Odulfo y Sabogal Neira, Daniel (2010). Las prácticas de mercadeo intuitivo en el turismo popular. En Perfiles Libertadores, Vol. XIX, N. ${ }^{\circ}$ 33, pp. 131 153.

Arámbulo III, Primo; Almeida, Claudio R; Cuéllar S, Juan y Belotto, Albino J (1995). La venta de alimentos en la vía pública de América Latina, Bol oficina Sanit Panam, N. 118, Vol. 2, pp. 97-107.

Borden, Neil (1964).The Concept of the Marketing Mix. En: Journal of Advertising Research, Vol. II (Classics), pp. 7-12.

Camargo Hernández, David Francisco (2005). Actividades económicas informales y tributación. Edición electrónica por Eumed.net, 75p.

Cárdenas, Mauricio y Mejía, Carolina (2007). Informalidad en Colombia: Nueva Evidencia. En: Working paper series - Documentos de trabajo Fedesarrollo N. ${ }^{\circ} 35,43 p$.

CESOP - Centro de Estudios Sociales y de Opinión Pública- (2005). Comercio Ambulante. En: Reporte Temático No 2, p. 30.

DNP - Departamento Nacional de Planeación (2007). Política nacional para la transformación productiva y la promoción de las micro, pequeñas y medianas empresas: un esfuerzo público-privado. Documento CONPES, Departamento nacional de planeación, República de Colombia, 30p.

Drucker, Peter F. (2010). The Practice of Management. Harper Collins e-Books, 355p.

Firth, Alan. (2010). Etnometodología. En: Discurso y Sociedad, Vol. 4, N. 3, pp. 597-614.

Gómez Naranjo, Luis Guillermo; Gómez Agudelo, Yesid y Borráez Alvarez, Andrés Felipe (2005). Apuntes sobre la Economía Informal: Caso Medellín (Primera parte). En: Semestre Económico, Vol. 8, $N^{\circ} 15$, pp. 31-46.

Guataquí Roa, Juan Carlos; García Suaza, Andrés y Rodríguez Acosta, Mauricio (2011). El perfil 
Estrategias de mercadeo de los vendedores ambulantes

de la informalidad laboral en Colombia. En: Documentos de Trabajo $N^{\circ} 15,31 \mathrm{p}$.

Hart, Keith (1973). Informal Income Opportunities and Urban Employment in Ghana. En: Journal of Modern African Studies, Vol. 11, N. ${ }^{\circ}$ 1, pp. 61-89.

IDMC -Internal Displacement Monitoring Centre. (2014) Informe global de desplazamiento forzado. Noruega, 78p.

Jaramillo, Ana María; Villa, Marta Inés y Sánchez, Luz Amparo (2004). Miedo y desplazamiento. Experiencias y percepciones. Medellín, Colombia: Editorial Corporación Región, 306p.

Kotler, Philip y Armstrong, Gary (2013). Fundamentos de marketing. México: Pearson Educación

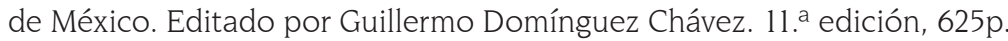

Miranda Camarena, Adrian Joaquín y Rizo Orozco, Soledad. (2010). Aspectos Generales de la Economía Informal. En: Letras Jurídicas. Primavera. N. ${ }^{\circ} 10$.

Mires, Fernando (1989) ¿Existe el sector informal? Una pregunta que también es un tema. Revista Foro \#9. Chile.

Ochoa Valencia, David y Ordóñez, Aura (2004). En: Informalidad en Colombia. Causas, efectos y características de la economía del rebusque. En: Estudios Gerenciales, Vol. 90, pp.103-116.

OIT - Organización Internacional del Trabajo (2005). Economía Informal en las Américas: situación actual, prioridades de políticas y buenas prácticas. En: XIII Conferencia Interamericana de Ministros de Trabajo de la OEA, 39p.

OIT - Organización Internacional del Trabajo (2013). La transición de la economía informal a la economía formal. En: Informe de la conferencia internacional del trabajo. Vol. 103, N. ${ }^{\circ} 1$. Ginebra, 93p.

OIT- Organización Internacional del Trabajo (2010). La extensión del ámbito de aplicación de la legislación laboral a la economía informal. En: Compendio de comentarios de los órganos de control de la OIT relativos a la economía informal. Suiza, 125p.

OIT-Organización Internacional del Trabajo (2002). Women and Men in the Informal Economy: A Statistical Picture. En: ILO Geneva. Switzerland, 110p.

Peres Rokhas, Vera (2010). El empleo en el sector informal colombiano : Concepto, origen y perspectiva de género. En: Management, Vol. XIX, N. ${ }^{\circ}$ 33, pp. 57-88.

Portes, Alejandro y Haller, William (2004). La economía informal. En: CEPAL Serie Políticas Sociales. Santiago de Chile. N. 100.

Sarria Icaza, Ana Mercedes y Tiribia, Lía. (2003). Economía popular. En: la Otra Economía, pp. 173-186.

Stanton, Etzel y Walter (2007) Fundamentos de marketing. Decimocuarta edición. México. McGraw-hill/Interamericana Editores, S. A.

Tokman, V. (2001). De la informalidad a la Modernidad. Santiago. Oficina internacional del trabajo. En: Boletín Cinterfor. $N^{\circ} 155$, pp. 9-32.

Vargas Martínez, Hermes Heriberto (2011). Fundamentos de mercadeo. Escuela Nacional Abierta y a Distancia (UNAD). En: Contenido didáctico del curso Fundamentos de Mercadeo, 236p. 
